\title{
The effects of attenuation and site on the spectra of microearthquakes in the Jubilee Hills region of Hyderabad, India
}

\author{
Saurabh Baruah ${ }^{1, *}$, Devajit Hazarika ${ }^{1}$, Naba K Gogor ${ }^{2}$ and P Solomon Raju ${ }^{2}$ \\ ${ }^{1}$ Geoscience Division, Regional Research Laboratory (CSIR), Jorhat 785 006, India. \\ ${ }^{2}$ National Geophysical Research Institute (CSIR), Hyderabad 500 00\%, India. \\ *e-mail: saurabhb_23@yahoo.com
}

Microearthquake spectra from Jubilee Hills, Hyderabad are analyzed to observe the effect of attenuation and site on these spectra. The ratios of spectral amplitudes at lower and higher frequency are measured for three different stations at varying epicentral distances to estimate $Q$ value for both P- and S-wave in near and sub-surface layer. Average estimates of Qp and Qs are 235 and 278 respectively. Value of Qs/Qp larger than 1.0 suggests dry crust for most of the Jubilee Hills region. The near-surface low $\mathrm{Qp}$ and $\mathrm{Qs}$ for $0 \mathrm{~km}$ to $0.9 \mathrm{~km}$ depth coincide with the soil layer, top and semi-weathered and highly fractured zone. In contrast, at a shallower depth beneath the Jubilee Hills area, Hyderabad, we obtain high Qp and Qs zone, which corresponds to the dense and high velocity rocks of the region. The varying corner frequencies for these spectra are inferred to be characteristics of site. Comparisons of disparity in spectral content with reference to hard rock site conclude that lithology of the northwest part of Jubilee Hills area amplify about twice the incoming seismic signal, as compared to the southern part best outlined at 8 to $10 \mathrm{~Hz}$ only.

\section{Introduction}

A seismogram reflects the effect of source and the path of propagation up to the receiver station. When we examine seismograms of local earthquakes for frequencies higher than $1 \mathrm{~Hz}$, these waveforms are usually complex. One can observe complex wave trains in addition to direct $\mathrm{P}$ and $\mathrm{S}$ waves in every seismogram. Wave trains following the direct $\mathrm{S}$ wave are called $\mathrm{S}$-wave trains and those between direct $\mathrm{P}$ and $\mathrm{S}$ waves are known as $\mathrm{P}$-wave trains. These waves help to estimate one of its elemental properties, i.e., attenuation. Attenuation allows one to infer the material and physical conditions of the structure underneath the source, site and the propagation pathway. Measurement of attenuation of direct wave and wave trains gives values for total seismic attenuation. In general, amplitude of the direct seismic wave usually decays exponentially with increasing travel distance. The decay rates are proportional to $Q^{-1}$, which characterizes attenuation. The decay is due to geometrical spreading, intrinsic and scattering attenuation. According to Sato (1977), high frequency contents of direct waves help in the determination of attenuation parameter $(\mathrm{Q})$. The reasons why near to sub-surface Qp and Qs, the attenuation parameter of $\mathrm{P}$ and $\mathrm{S}$ is so important are:

- site effect causes waveform distortion and that makes source study difficult

- an estimate of stress induced features and the sub-surface lithology.

Vassilou et al (1982) gave the general observation of $\mathrm{Qp}$ and Qs relations in sedimentary rocks; $\mathrm{Qp}=\mathrm{Qs}$ for dry rocks, $Q p \geq Q$ s for fully saturated rocks and Qp $<$ Qs for partial saturation. Johnston and Toksoz (1980) report that Qs is slightly greater

Keywords. Qp and Qs value; attenuation and spectral amplitude. 

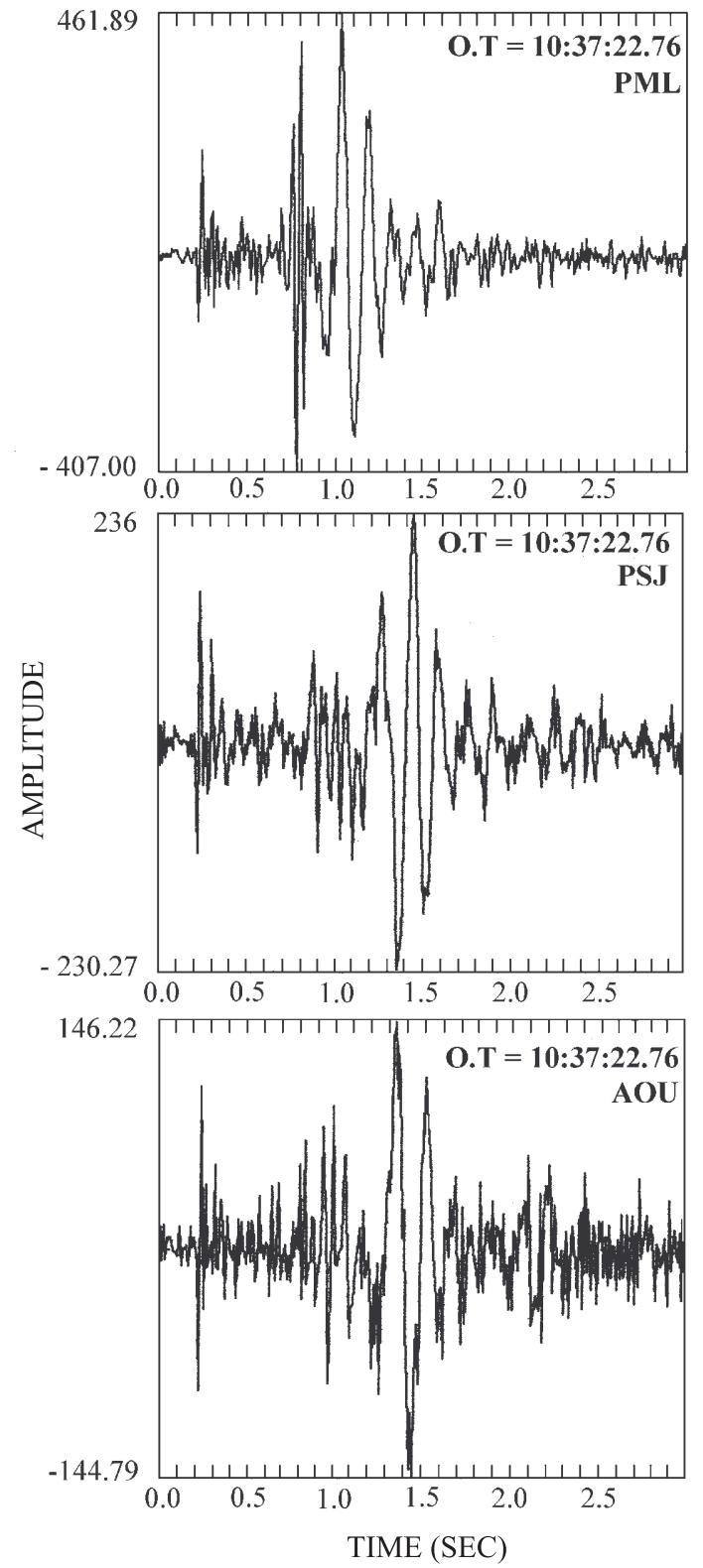

Figure 1. Vertical component seismogram of a microearthquake recorded by all the three stations of the network. The origin time and station code are indicated at top right corners. The amplitudes are in counts $(1$ count $=127 e-11 \mathrm{~m} / \mathrm{s})$.

than Qp for dry areas. Generally Qp is higher than Qs. This is reported by Anderson et al (1965) with $\mathrm{Qp}=9 / 4 \mathrm{Qs}$. However, Rautian et al (1978) indicate that Qs is larger than Qp for the crustal paths, so that Qs $\sim 1.78 \mathrm{Qp}$. These differences in Qp/Qs found in attenuation mechanism are accredited to the different heterogeneities in the uppermost crust.

The presence of heterogeneity in the earth crust though for a smaller region also contributes in an essential manner towards estimating the attenuation parameter. Several authors, e.g., Cranswick
(1988); Sato and Fehler (1998) have observed that even in small rock samples, heterogeneity of the scale of grain sizes plays an important role in the propagation of ultrasonic waves of the order of MHz. When the seismograms originated from a very highly localized area of approximately $24 \mathrm{~km}^{2}$ from Jubilee Hills, Hyderabad were examined, it was found that amplitudes of $\mathrm{P}$ - and S-wave trains decay are extremely different with complex spectral amplitude domain even though recording stations are equipped with similar instrumentation. Figure 1 depicts an event (all vertical component seismogram) recorded by three stations. All the three seismograms encompass different spectral content although the recording stations are very closely spaced. Recognizing the complexity of the seismogram, a simple technique has been adopted to address the attenuation in the region. The local site effect at a receiver that causes enormous scatter is considered while addressing the attenuation.

The manuscript is divided into two parts. Initial portion deals with the estimation of attenuation parameter (Q) of direct waves particularly at an average low and high frequency that travel throughout the near and sub-surface layer of the studied region. Qp and Qs are determined from alteration in the amount of high frequency energy recorded relative to the low frequency energy towards the local microearthquake activity, as a function of epicentral distance/travel time. Attenuation mechanism that is functioning in the region is studied with absolute values of Qp, Qs and their ratio.

The later part examines the individuality of the spectra of microearthquakes with an attempt to study the difference of the spectral content at the receiving site for different micro-tremors when the azimuth and incidence angle is practically the same for all three stations. The spectral ratio with respect to a reference site gives an idea of the site effect in the region supplemented by litholog information.

In this study, the technique adopted by Tsujiura (1966), modified by Frankel (1982), has been used to estimate the Qp and Qs for Jubillee Hills microearthquakes. The results of this study are highlighted here.

\section{Geological settings}

The area of the present study, delimited by latitude $17.41^{\circ}$ to $17.45^{\circ} \mathrm{N}$ and longitude $78.36^{\circ}$ to $78.42^{\circ} \mathrm{E}$, covers the Jubilee Hills area of Hyderabad. Broadly, the area is composed of Archean granites and gneisses occurring as prominent hillocks with the existence of a WNW-ESE shear zone 


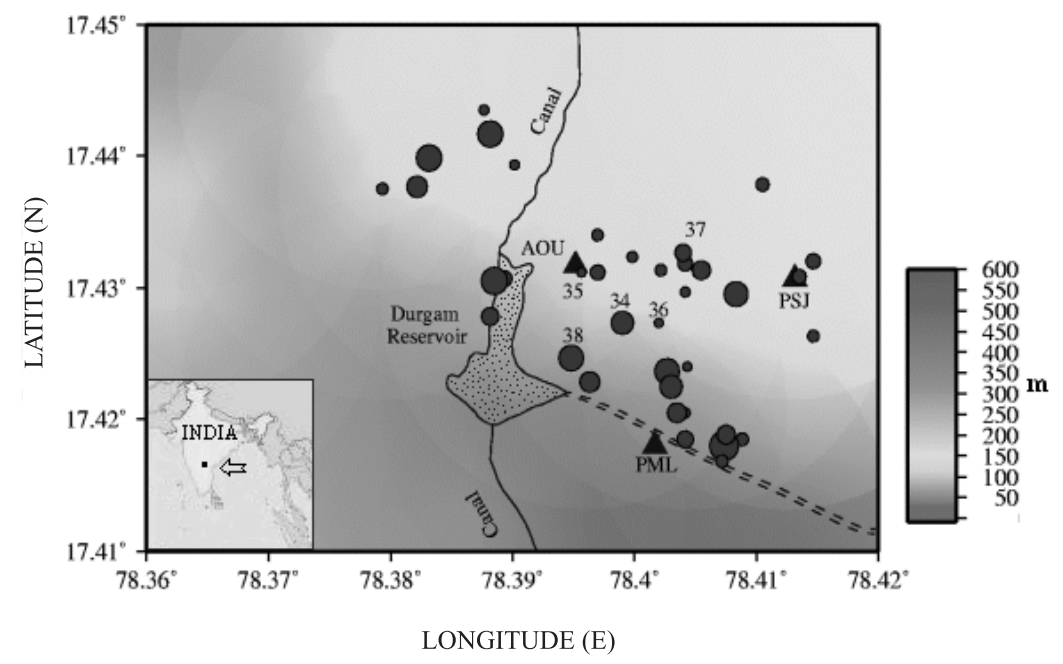

Figure 2. Epicentral map of the microearthquakes occurred in the Jubilee Hills region [as indicated by filled dark square in the key map of India (inset)] showing station locations of AOU, PML and PSJ. The numbered events are used to observe the disparity of spectral content. Number denotes the event shown in table 1. Dashed line indicates shear zone. The coloured scale in the right indicates the topographic elevation measured in meters.

extending from Banzara Lake near Hotel Taj Residency, passes through KBR-National Park and terminates near Durgam reservoir (figure 2). Seismic activity in the region is mainly associated with far field compression due to motion of the Indian plate and together with the pre-existing faults and weak zones in the form of morphotectonic knots in the Jubilee Hills. A 3D relief of Hyderabad mapped by Singh et al (2004) shows an undulating basinal structure with an average depth of about $4 \mathrm{~km}$ with the central part of Hyderabad granite pluton forming a circular bowl-like depression encompassing the Jubilee Hills.

\section{Data}

The studied area, i.e., the Jubilee Hills area of Hyderabad, India experienced a number of microseismic activities in the recent past. On October 15, 1998, the National Geophysical Research Institute (NGRI), Hyderabad seismological observatory recorded four tremors originating from Jubilee Hills area, Hyderabad. Since then a temporary network of three stations namely PML, PSJ, and AOU have been established up to November 5, 1998 to record the aftershocks as shown in figure 2. This network consists of three digital stations equipped with short period L4C-3D, three-component seismometer and GPS synchronized 24-bit REFTEK 72A-08 digitizer. It was a continuous mode of recording in all the three stations having a sampling rate of 100 samples/second. These stations have the capacity of recording high frequency seismic energy up to $50 \mathrm{~Hz}$. A total of 496 tremors were recorded during the period of deployment.
However, only thirty-eight tremors recorded by all the three stations, could be located accurately (Raju et al 2000). Table 1 shows the located events recorded during the period used for attenuation studies along with solution quality. An epicentral plot can be seen in figure 2. The depth of these events varies from $0.09 \mathrm{~km}$ to $2.49 \mathrm{~km}$. Most of the microearthquakes are felt in the area. More than half of the events occurred within the depth of nearly one kilometer. The root mean square value for hypocentral parameter is below $0.25 \mathrm{~s}$. Crustal velocity model by Gaur and Priestley (1997) is used for computation of the hypocentral parameters. So far as the lithology underneath the site of the stations is concerned, the exact litholog information by drilling, etc. is not available for these stations. However, the near-surface and subsurface geophysical investigations by Murthy and Raghavan (2002); Krishnamurthy et al (2003) and Singh et al (2004) indicate a highly weathered zone followed by fractured granite underneath the area where AOU, PML stations are situated and that hard granite existed under PSJ.

In order to determine the spectra of the $\mathrm{P}$ and $\mathrm{S}$ waves, initial $\mathrm{P}$ - and $\mathrm{S}$-wave arrivals of the microearthquake are used. Selection of small sample length is made because the variation of travel time is not important at the beginning and end of the sample. The next step is the baseline correction and trend removal. Baseline has been calculated as arithmetic average from the first 150 samples. The time history of the trend is calculated as a running arithmetic average while trend is subtracted from the original record. After this, the spectra are calculated using a Fast Fourier Transform and corrected for instrument response. 
Table 1. List of tremors and epicentral parameters.

\begin{tabular}{|c|c|c|c|c|c|c|c|c|c|c|c|c|c|}
\hline \multirow{2}{*}{$\begin{array}{c}\text { Event } \\
\text { No }\end{array}$} & \multirow{2}{*}{\multicolumn{3}{|c|}{$\begin{array}{c}\text { Date } \\
\text { YY MM DD }\end{array}$}} & \multicolumn{3}{|c|}{ Origin } & \multirow{2}{*}{$\begin{array}{l}\text { Lat. N } \\
\text { Deg. }\end{array}$} & \multirow{2}{*}{$\begin{array}{l}\text { Long. E } \\
\text { Deg. }\end{array}$} & \multirow{2}{*}{$\begin{array}{l}\text { Depth } \\
\text { km }\end{array}$} & \multirow{2}{*}{$\begin{array}{c}\text { Magnitude } \\
\qquad M_{D} A\end{array}$} & \multicolumn{3}{|c|}{ RMS } \\
\hline & & & & $\mathrm{HH}$ & MM & $\mathrm{SS}$ & & & & & No & $\mathrm{Sec}$ & $\mathrm{QM}$ \\
\hline 1 & 98 & 10 & 17 & 10 & 33 & 46.75 & 17.424 & 78.403 & 0.13 & 0.69 & 6 & 0.03 & B1 \\
\hline 2 & 98 & 10 & 17 & 10 & 58 & 27.75 & 17.423 & 78.403 & 0.64 & 0.56 & 6 & 0.08 & B1 \\
\hline 3 & 98 & 10 & 17 & 11 & 46 & 44.70 & 17.432 & 78.404 & 3.72 & 0.30 & 6 & 0.06 & C1 \\
\hline 4 & 98 & 10 & 17 & 13 & 26 & 57.73 & 17.431 & 78.414 & 1.82 & 0.29 & 6 & 0.09 & C1 \\
\hline 5 & 98 & 10 & 17 & 21 & 58 & 39.64 & 17.432 & 78.415 & 1.00 & 0.25 & 6 & 0.20 & $\mathrm{C} 1$ \\
\hline 6 & 98 & 10 & 17 & 22 & 27 & 31.59 & 17.432 & 78.415 & 1.00 & 0.31 & 6 & 0.20 & C1 \\
\hline 7 & 98 & 10 & 17 & 23 & 39 & 2.36 & 17.430 & 78.404 & 1.38 & 0.19 & 6 & 0.01 & C1 \\
\hline 8 & 98 & 10 & 18 & 00 & 43 & 54.77 & 17.419 & 78.409 & 0.37 & 0.25 & 6 & 0.04 & $\mathrm{C} 1$ \\
\hline 9 & 98 & 10 & 18 & 00 & 02 & 32.19 & 17.438 & 78.411 & 2.00 & 0.27 & 6 & 0.13 & $\mathrm{C} 1$ \\
\hline 10 & 98 & 10 & 18 & 00 & 43 & 54.76 & 17.418 & 78.407 & 0.71 & 0.90 & 6 & 0.04 & C1 \\
\hline 11 & 98 & 10 & 18 & 01 & 34 & 16.56 & 17.419 & 78.404 & 1.00 & 0.34 & 6 & 0.05 & $\mathrm{C} 1$ \\
\hline 12 & 98 & 10 & 18 & 02 & 24 & 6.72 & 17.417 & 78.407 & 0.48 & 0.26 & 6 & 0.01 & $\mathrm{C} 1$ \\
\hline 13 & 98 & 10 & 19 & 00 & 40 & 29.12 & 17.426 & 78.415 & 0.49 & 0.24 & 6 & 0.03 & $\mathrm{C} 1$ \\
\hline 14 & 98 & 10 & 19 & 06 & 18 & 55.79 & 17.431 & 78.406 & 1.00 & 0.38 & 6 & 0.04 & $\mathrm{C} 1$ \\
\hline 15 & 98 & 10 & 19 & 08 & 54 & 44.52 & 17.419 & 78.408 & 0.95 & 0.37 & 6 & 0.06 & $\mathrm{C} 1$ \\
\hline 16 & 98 & 10 & 22 & 07 & 22 & 28.06 & 17.439 & 78.390 & 2.29 & 0.21 & 6 & 0.00 & C1 \\
\hline 17 & 98 & 10 & 22 & 07 & 31 & 19.06 & 17.444 & 78.388 & 2.20 & 0.20 & 6 & 0.01 & $\mathrm{C} 1$ \\
\hline 18 & 98 & 10 & 23 & 02 & 31 & 34.96 & 17.424 & 78.404 & 0.09 & 0.10 & 6 & 0.04 & B1 \\
\hline 19 & 98 & 10 & 23 & 13 & 38 & 45.28 & 17.421 & 78.404 & 0.77 & 0.18 & 6 & 0.02 & B1 \\
\hline 20 & 98 & 10 & 23 & 14 & 58 & 20.15 & 17.431 & 78.402 & 0.33 & 0.23 & 6 & 0.05 & B1 \\
\hline 21 & 98 & 10 & 26 & 23 & 48 & 57.05 & 17.442 & 78.388 & 2.28 & 0.82 & 6 & 0.01 & $\mathrm{C} 1$ \\
\hline 22 & 98 & 10 & 27 & 08 & 38 & 15.04 & 17.431 & 78.389 & 1.04 & 0.33 & 6 & 0.02 & $\mathrm{C} 1$ \\
\hline 23 & 98 & 10 & 28 & 08 & 44 & 5.58 & 17.428 & 78.388 & 0.89 & 0.36 & 6 & 0.02 & $\mathrm{C} 1$ \\
\hline 24 & 98 & 10 & 29 & 20 & 09 & 45.64 & 17.432 & 78.400 & 0.58 & 0.22 & 6 & 0.01 & $\mathrm{C} 1$ \\
\hline 25 & 98 & 10 & 30 & 01 & 25 & 30.80 & 17.434 & 78.397 & 0.80 & 0.23 & 6 & 0.20 & C1 \\
\hline 26 & 98 & 10 & 31 & 18 & 11 & 12.95 & 17.431 & 78.397 & 0.72 & 0.31 & 6 & 0.02 & B1 \\
\hline 27 & 98 & 11 & 01 & 01 & 09 & 17.23 & 17.438 & 78.379 & 2.49 & 0.24 & 6 & 0.02 & $\mathrm{C} 1$ \\
\hline 28 & 98 & 11 & 02 & 09 & 02 & 2.09 & 17.431 & 78.389 & 1.21 & 0.91 & 6 & 0.01 & C1 \\
\hline 29 & 98 & 11 & 02 & 15 & 28 & 10.94 & 17.430 & 78.408 & 0.77 & 0.52 & 6 & 0.02 & B1 \\
\hline 30 & 98 & 11 & 03 & 08 & 40 & 27.79 & 17.438 & 78.382 & 2.33 & 0.42 & 6 & 0.01 & $\mathrm{C} 1$ \\
\hline 31 & 98 & 11 & 03 & 08 & 47 & 49.43 & 17.440 & 78.383 & 2.22 & 0.62 & 6 & 0.01 & $\mathrm{C} 1$ \\
\hline 32 & 98 & 11 & 03 & 09 & 09 & 21.22 & 17.423 & 78.396 & 0.43 & 0.54 & 6 & 0.01 & $\mathrm{C} 1$ \\
\hline 33 & 98 & 11 & 04 & 16 & 53 & 50.50 & 17.421 & 78.404 & 0.35 & 0.46 & 6 & 0.03 & B1 \\
\hline 34 & 98 & 11 & 04 & 09 & 32 & 46.07 & 17.427 & 78.399 & 0.80 & 0.49 & 6 & 0.09 & B1 \\
\hline 35 & 98 & 11 & 04 & 12 & 18 & 32.66 & 17.431 & 78.396 & 2.28 & 0.09 & 6 & 0.24 & B1 \\
\hline 36 & 98 & 11 & 04 & 12 & 41 & 36.23 & 17.427 & 78.402 & 1.21 & 0.09 & 6 & 0.16 & B1 \\
\hline 37 & 98 & 11 & 04 & 16 & 53 & 47.58 & 17.433 & 78.404 & 2.10 & 0.34 & 6 & 0.14 & B1 \\
\hline 38 & 98 & 11 & 05 & 10 & 37 & 22.76 & 17.425 & 78.395 & 0.90 & 0.57 & 6 & 0.05 & A1 \\
\hline
\end{tabular}

\section{Determination of Qp and Qs}

It is practical that higher frequency content is supplementary in very nearby events. This observation suggests that the co-efficient of attenuation could be determined from the changes in the spectral shape of earthquakes at a very nearby distance from a fixed receiver. Figure 3(a) shows the $\mathrm{P}$ waves and their displacement spectra at station AOU of two earthquakes at nearest and farthest distances. The spectra are determined for the first
$0.4 \mathrm{~s}$ of the $\mathrm{P}$ waves of the events. Travel time of $\mathrm{P}$ wave of the nearest event is $2.95 \mathrm{~s}$ while distant event has the travel time of $4.51 \mathrm{~s}$. The nearer event is distinguished by a reasonably higher spectral amplitude content than that obtained from the distant event as viewed from the logarithmic amplitude scale along Y-axis. Particularly for these two earthquakes the spectral content shows variation in amplitude from $2 \mathrm{~Hz}$ to approximately $28 \mathrm{~Hz}$. At a frequency of $28 \mathrm{~Hz}$ and beyond there is a sharp fall in amplitude. Spectral amplitude 

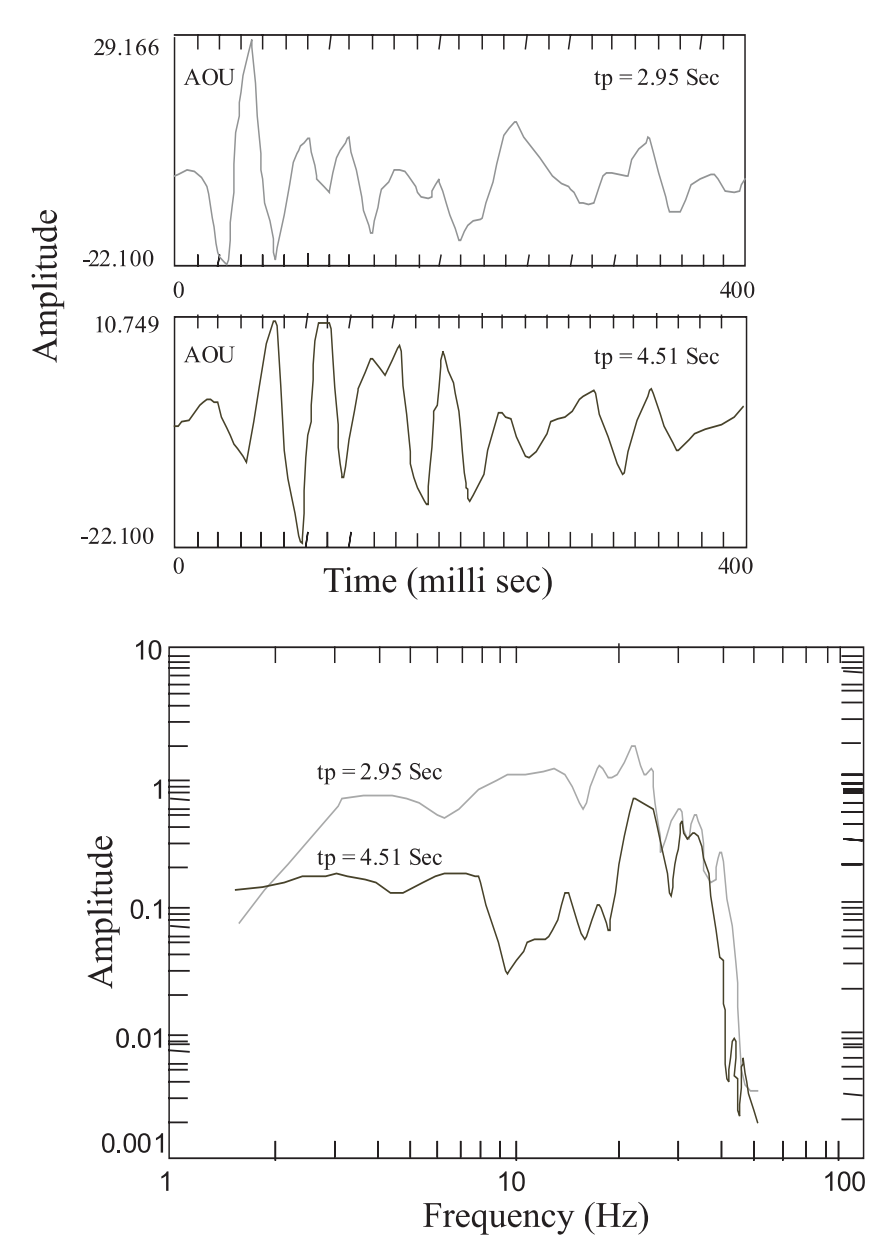

(a)

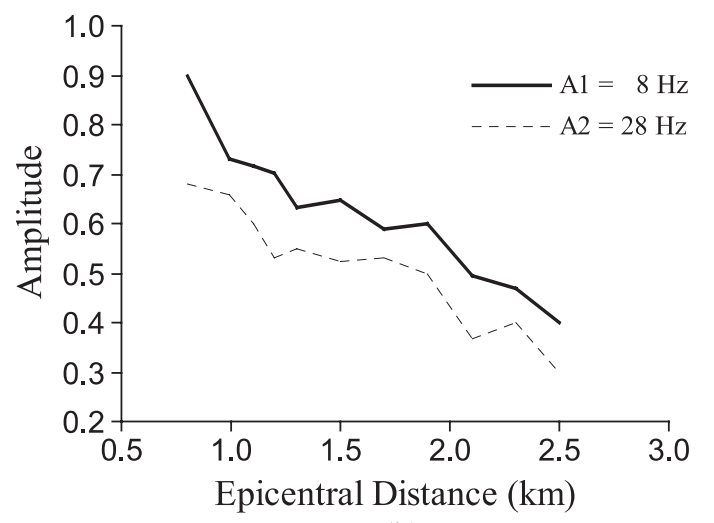

(b)

Figure 3. (a) Effects of distance on microearthquake spectra. (Top) $\mathrm{P}$ waves at AOU for two events at different epicentral distances from AOU. (Bottom) P-wave displacement spectra. The solid trace is the spectrum of an event with travel time of $\mathrm{P}, \mathrm{tp}=4.51 \mathrm{~s}$. The thin trace represents the spectrum of the event with $t p=2.95 \mathrm{~s}$. Note that the spectral amplitude at $28 \mathrm{~Hz}$ relative to the amplitude at $8 \mathrm{~Hz}$ is much larger for the nearest event than for the distant one. The unit of amplitude of displacement spectra and Fast Fourier Transformation are in counts $(1$ count $=127 e-11 \mathrm{~m} / \mathrm{s})$ and $\mathrm{Cm} / \mathrm{Hz}$ respectively. (b) Decay of spectral amplitude with respect to epicentral distance at lower $(8 \mathrm{~Hz})$ and higher frequency $(28 \mathrm{~Hz})$ for the most of the events studied. in lower frequency range seems to vary between 6 and $10 \mathrm{~Hz}$ while for higher frequency range this is between $26 \mathrm{~Hz}$ and $30 \mathrm{~Hz}$ in case of most events. Hence the spectral amplitudes are anticipated by averaging the amplitude between 6 and $10 \mathrm{~Hz}$ and $26 \mathrm{~Hz}$ and $30 \mathrm{~Hz}$ to obtain the $8 \mathrm{~Hz}$ and $28 \mathrm{~Hz}$ spectral levels respectively. The spectral amplitude at $28 \mathrm{~Hz}$ relative to the amplitude at $8 \mathrm{~Hz}$ is much larger for the nearest event than for the distant one. The dependence of spectral content over epicentral distance for most of the events can be observed in figure 3(b) where the spectral content at $8 \mathrm{~Hz}$ and $28 \mathrm{~Hz}$ decreases with the increase of epicentral distance.

In the method of determining Q, two basic assumptions are made. Primarily it is assumed that $\mathrm{Q}$ is constant over the frequency band studied, 8 to $28 \mathrm{~Hz}$. If $\mathrm{Q}$ is not constant in this band, then the $\mathrm{Q}$ values to be obtained in this study will represent a complicated average of the actual range of $\mathrm{Q}$ for these frequencies. The spectral shapes of these events between 8 and $28 \mathrm{~Hz}$ are to be identical at the earthquake source. Secondly, it is also assumed that the source spectra of all the earthquakes in the study have the same values for the ratio of their $28 \mathrm{~Hz} / 8 \mathrm{~Hz}$ amplitudes. The validity of this assumption can be tested by examining the scatter in the plots of spectral ratio against travel time. If the source spectra of events of similar travel times are significantly variable in the pass band, a difference in their spectral ratios should be apparent. The ratio of the spectral amplitude at 8 and $28 \mathrm{~Hz}$ has been observed for a number of earthquakes at different epicentral distances from all the three stations of the network. When the logarithms of the ratio are plotted against the travel time for the seismic waves, the slope of the data is proportional to $1 / \mathrm{Q}$. The variation in $\mathrm{Q}$ due to scattering and the amplitude ratio dependent on the shape of spectra invalidate the effect of geometrical spreading.

The spectral amplitude of a body wave at frequency $f$ is related to the travel time of seismic wave represented by:

$$
A(f) \alpha\left[\frac{A_{o}(f) R(f) e^{-\pi f t / Q}}{r}\right],
$$

where $A_{o}(f)$, is the spectral amplitude at the source.

$A(f)$ is dependent on the travel time of the seismic wave $t$ and the source-receiver distance $r . R(f)$ is the response function of the site to incoming seismic radiation. This transfer function basically imparts effects, such as attenuation.

For two different frequencies $f 1$ and $f 2$, the natural logarithm of their amplitude ratio is: 


$$
\begin{aligned}
\ln [A(f 1) / A(f 2)]= & \ln \left[A_{o}(f 1) / A_{o}(f 2)\right] \\
& +\ln [R(f 1) / R(f 2)] \\
& -[\pi(f 1-f 2) t / Q]
\end{aligned}
$$

If $A_{o}(f 1) / A_{o}(f 2)$ and $R(f 1) / R(f 2)$ are constant for all events under study and independent of travel time of the earthquakes used, then $\ln [A(f 1) / A(f 2)]$ plotted against $t$ will have a slope of $\pi(f 2-f 1) / Q$. In this study $f 1$ is chosen at $28 \mathrm{~Hz}$ and $f 2$ is $8 \mathrm{~Hz}$. The slope contains the information about the attenuation and travel time of $\mathrm{P}$ and S. $R(f 1) / R(f 2)$ will be constant for all of the earthquakes as long as the same station was used to determine the amplitude ratios and the site response is not a function of the azimuth or angle of incidence of the incoming seismic waves.

Qp and Qs are determined using events listed in table 1. Vertical component seismograms are used for estimation of $\mathrm{P}$-wave spectra. The spectral amplitude ratios of the $\mathrm{P}$ waves for these events are plotted as a function of $\mathrm{P}$-wave travel time (tp) at station AOU (figure 4a). Figure 4(a) displays two trends: logarithmic ratio of $28 \mathrm{~Hz}$ amplitude $/ 8 \mathrm{~Hz}$ amplitude decreases consistently with travel time for those events having $\mathrm{P}$-wave travel time greater than $2.8 \mathrm{~s}$. Simultaneously events having less than $2.8 \mathrm{~s}$ P-wave travel time do not show any dependence with travel time. For this reason events having travel time greater than $2.8 \mathrm{~s}$ are considered and yield a Qp of 179 for AOU.

Likewise, S-wave spectra are determined using the horizontal component seismograms. Amplitude ratios of $\mathrm{S}$ waves plotted against travel time for $\mathrm{AOU}$ are shown in figure 4(b). Figure 4(b) also shows two trends. Events with S-wave travel times greater than $3.3 \mathrm{~s}$ exhibit spectral ratios whose logarithms decrease with travel time. These events provide an estimate of Qs of 238, for travel times larger than $3.3 \mathrm{~s}$. However, earthquakes with S-wave travel times less than $3.3 \mathrm{~s}$ display amplitude ratios, which do not change notably with travel time. Qp and Qs estimated for AOU indicate that they are different for these paths. The Y-intercepts of the lines that fit the data presented in figures 4(a) and 4(b) provide information on the differences in $\mathrm{P}$ - and S-wave spectra. These differences in the ratios extrapolated to zero travel time reflect variations of the spectra at the source and/or characteristics of the receiver site.

Similarly the spectral ratios of both $\mathrm{P}$ and $\mathrm{S}$ waves for the events recorded at station PSJ are studied as a function of travel time. Figure 5(a) and 5(b) indicates that the spectral ratios of both $\mathrm{P}$ and $\mathrm{S}$ waves at PSJ decrease approximately at around $3.3 \mathrm{~s}$ of travel time. The PSJ data yield a
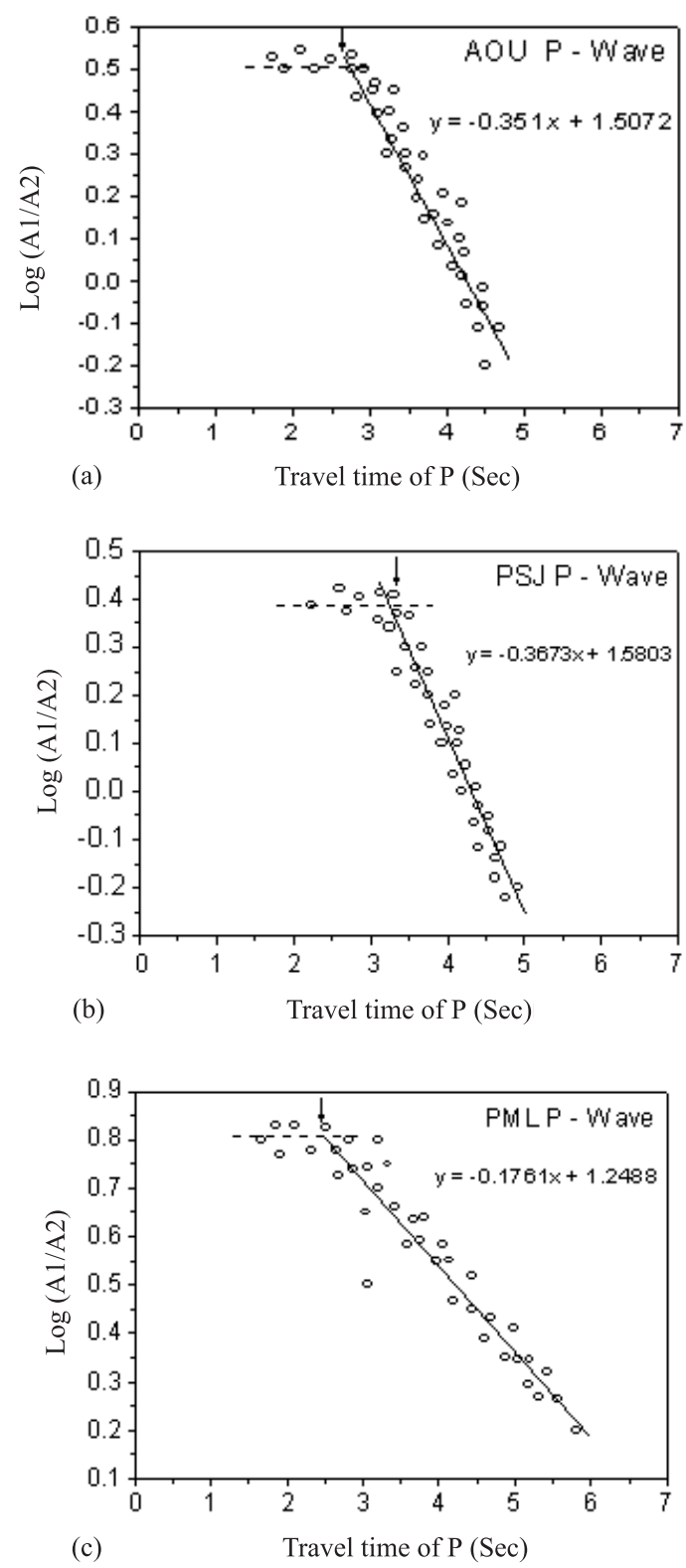

Figure 4. (a) $\log$ of $28 \mathrm{~Hz}$ amplitude $/ 8 \mathrm{~Hz}$ amplitude plotted against travel time (tp) of each earthquake for $\mathrm{P}$-wave at $\mathrm{AOU}$. The line drawn through the data represents the best fit for events with travel time greater than $2.8 \mathrm{~s}$ as indicated by arrow. (b) Same as in (a) but using P-wave spectra at PSJ. The line drawn through the data represents the best fit for events with travel time greater than $3.3 \mathrm{~s}$. (c) Same as in (a) but using P-wave spectra at PML. The line drawn through the data represents the best fit for events with travel time greater than $2.5 \mathrm{~s}$.

Qp of 179 using 32 events and a Qs of 209 from the ratio of the same number of events. The logarithm of the $\mathrm{Y}$-intercept for the $\mathrm{P}$-wave amplitude ratio at zero travel time is 1.5803 . The logarithm of the $\mathrm{S}$-wave amplitude ratio at zero travel time is calculated as 1.5816. This similarity in Y-intercepts between the P-and S-wave data signifies that the frequency content between $\mathrm{P}$ and $\mathrm{S}$ waves of similar 

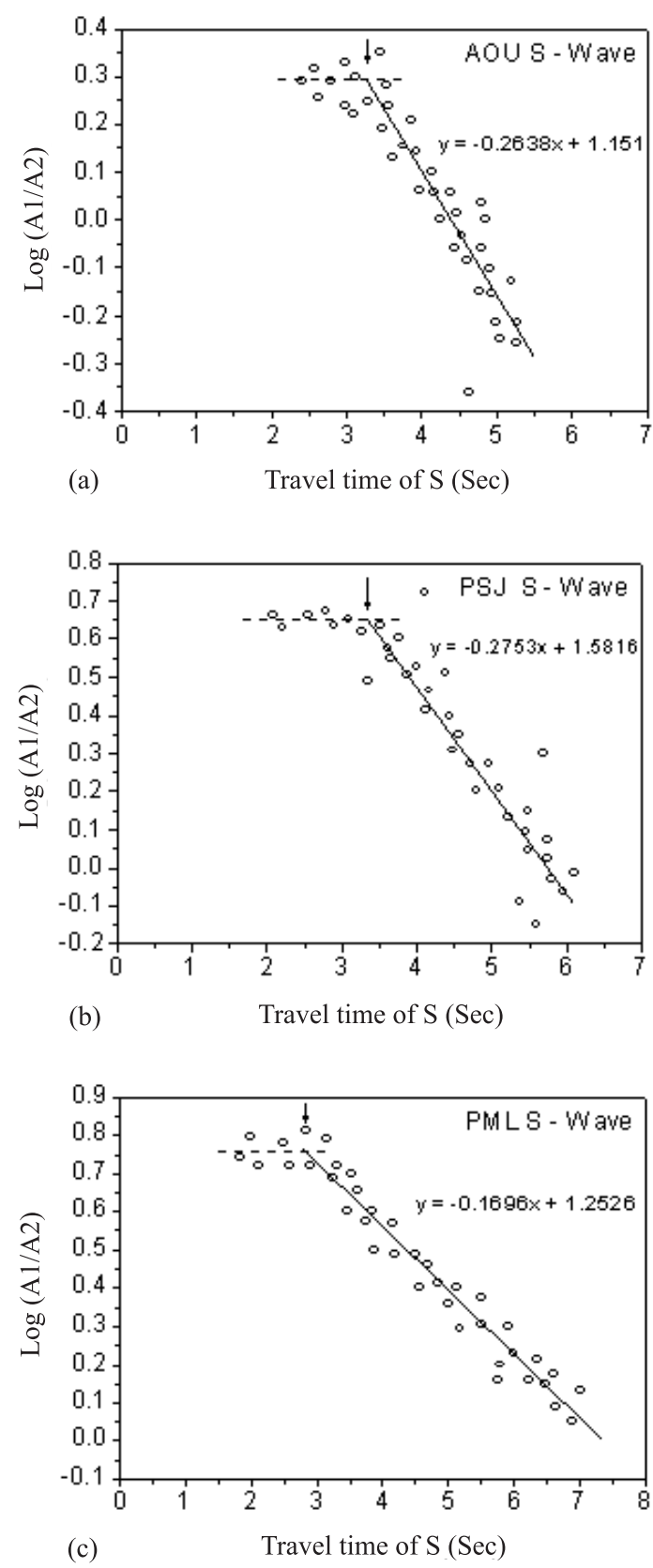

Figure 5. (a) Log of $28 \mathrm{~Hz}$ amplitude/ $8 \mathrm{~Hz}$ amplitude plotted against travel time (ts) of each earthquake for S-wave at AOU. The line drawn through the data represents the best fit for events with travel time greater than $3.3 \mathrm{~s}$. (b) Same as in (a) using S-wave spectra at PSJ. The line drawn through the data represents the best fit for events with travel time greater than 3.35 s. (c) Same as in (a) but using S-wave spectra at PML. The line drawn through the data represents the best fit for events with travel time greater than $3.4 \mathrm{~s}$.

travel times is a result of source effects only, not the site response. Figures 4(c) and 5(c) show the slope of amplitude ratio and travel time yields a $\mathrm{Qp}$ of 356.0 and of Qs 370.0 at PML. Qp and Qs values obtained in this study are compiled in table 2 . The average estimate of $\mathrm{Qp}$ and Qs from three stations are 235.5 and 278.8 respectively. In addition,
Table 2. Estimation of $Q$ determined from three stations of the network.

\begin{tabular}{ccccc}
\hline & AOU & PSJ & PML & Average \\
\hline $\mathrm{Qp}$ & 178.9 & 170.9 & 356.6 & 235.5 \\
$\mathrm{Qs}$ & 238.0 & 228.1 & 370.3 & 278.8 \\
\hline
\end{tabular}

to observe the variation of $\mathrm{Q}$ values with depth, the spectral ratios are calculated separately at two different thicknesses. First, the ratio is calculated for the soil layer, top and semi-weathered and highly fractured zone, i.e., for $0 \mathrm{~km}$ up to the depth of $0.9 \mathrm{~km}$. Qp and Qs estimated for this formation are 225 and 148 respectively. Second, the ratios are observed for the events that occurred between the depth ranges of $0.9 \mathrm{~km}$ and $2.8 \mathrm{~km}$ characterized by granite. It's average Qp and Qs are 260 and 255 respectively. The increase in Qp and Qs is very much evident with reference to the increase in depth.

\section{Site effect and corner frequency}

Although the epicenters are located very nearby the stations, it is implicit that the effect of crustal attenuation is relatively small. However, effect of site are observed from the spectra of the same event at least for two different stations.

Spectra at AOU and PSJ: examining the P-wave spectra at two different stations AOU and PSJ of the network indicates the implication of site effect. Figure 6 shows the spectra at AOU and PSJ for the same event. The $\mathrm{P}$-wave spectra at $\mathrm{AOU}$ in figure 6 exhibit corner frequencies at $17 \mathrm{~Hz}$ while it is higher, i.e., $26 \mathrm{~Hz}$ for PSJ. It is seen very clearly that corner frequencies of the $\mathrm{P}$-wave spectra observed at these two sites appear to be characteristics of the sites in spite of short epicentral distance. The differences in the corner frequencies may represent the varying rupture area at source. It may also be attributed to the varying lithology at the receiving site within these nearby stations. The higher corner frequencies at PSJ indicate heterogeneity beneath the station also seen in near surface litholog data (Krishnamurthy et al 2003). However, the corner frequencies of S-wave spectra for AOU and PSJ exhibit marginal difference. Consequently it is estimated that the errors in the estimation of the $\mathrm{P}$-wave and $\mathrm{S}$-wave corner frequencies are $\pm 4 \mathrm{~Hz}$ and $\pm 2 \mathrm{~Hz}$ respectively. Errors estimated are larger for $\mathrm{P}$-wave corner frequencies because the higher frequencies are compressed on the logarithmic scale that is used when these spectra are displayed.

Differences in spectra of direct $\mathrm{P}$ and $\mathrm{S}$ waves along with respective scattered waves for an event, 

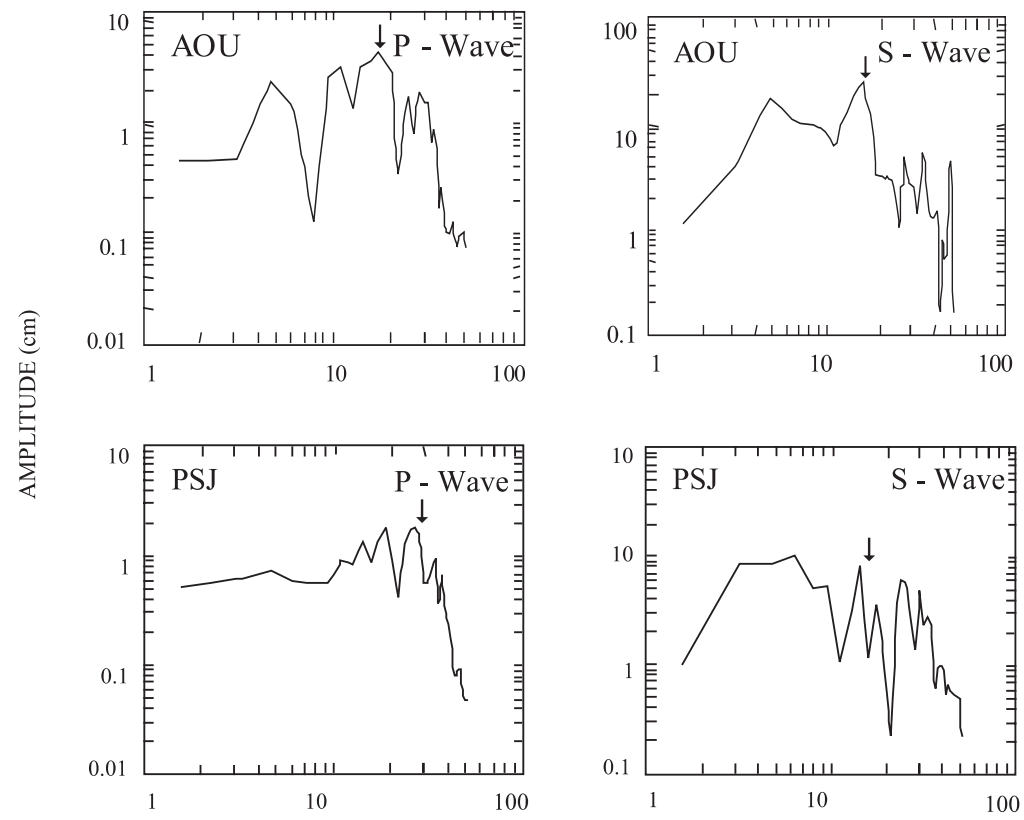

FREQUENCY $(\mathrm{Hz})$

Figure 6. Comparison of $\mathrm{P}$-wave and S-wave displacement spectra of the event (no. 38 of table 1 as in figure 1 ) at AOU and PSJ. Note that the corner frequency for P-wave is higher at PSJ than AOU. The respective corner frequencies are indicated by arrow marks.

which is located within the network, are observed at PSJ station (figure 7). The power spectra of the initial $0.2 \mathrm{~s}$ duration of the $\mathrm{P}$-wave (the direct and scattered wave) exhibit a peak at about $37 \mathrm{~Hz}$. Following the P-direct wave the $1.30 \mathrm{~s}$ duration of the S-wave (direct and scattered wave) spectra exhibit a peak at about $5 \mathrm{~Hz}$. The peak at the corresponding frequency for S-wave clearly contains higher energy in comparison to that of direct $\mathrm{P}$ wave spectra. The variations in maximum dominant frequency for the direct waves are inherited from the properties of the site and path.

\section{Spectral content}

An effort has also been made to study the disparity of the spectral content for records of local events, when the epicentral distance and the incident angle are practically the same for all the three stations. First we have selected PSJ as 'Hard rock site' by following Krishnamurthy et al (2003), Murthy and Raghavan (2002) and therefore is a reference station according to Steidl et al (1996). The spectral ratios are calculated with respect to this station. The entire waveform is smoothed by linear regression to restrain some redundant signal existing in the raw waveform which in particular throw 'artificial' enlargement to the spectral ratio. Event nos. 34, 35, 36, 37, 38 as in table 1 are used to observe spectral content. Emphasis is given to these events because of higher signal/noise ratio so that the waveforms are clear, free from noise. Only vertical component records are used. Five spectral ratios for AOU/PSJ are shown in figure 8 (a) together with an average spectral ratio out of these five events. Moderate dispersion of the spectral ratios is observed. The average spectral ratio so obtained is more or less stable. Fluctuation of average spectral ratio lies in the band of 1 to $3 \mathrm{~Hz}$. Similarly figure 8(b) shows the spectral ratio for PML/PSJ with five events along with their average spectral ratio. The deviation of average spectral ratio lies between 0.2 and $7.3 \mathrm{~Hz}$, i.e., not quite in the same band of oscillations of the average spectral ratio for AOU/PSJ. But on the contrary, the average spectral ratio PML/PSJ in figure 8(b) has strong amplification (maximum of 2.3 ) at a frequency around $9 \mathrm{~Hz}$. Comparison of the average spectral ratio of AOU/PSJ (bold line) and PML/PSJ (thin line) can be seen in figure $8(\mathrm{c})$. Figure 8(a), 8(b) and 8(c) concludes that the geological structures of the northwest part of Jubilee Hills area amplify about twice the incoming seismic signal, as compared with the southern part. This effect can be observed at 8 to $10 \mathrm{~Hz}$ only. No variation in average spectral ratio for AOU/PSJ and PML/PSJ can be seen within the range of 0.5 to $5 \mathrm{~Hz}$. Variation beyond $5 \mathrm{~Hz}$ up to $10 \mathrm{~Hz}$ indicates characteristics of the site at northern and southern parts of the region. As these events are from different directions, the average behaviour of spectral 


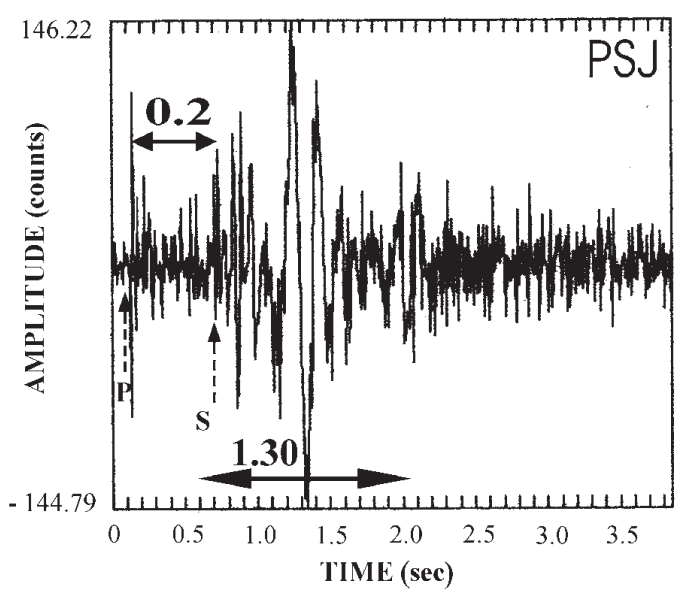

(a)

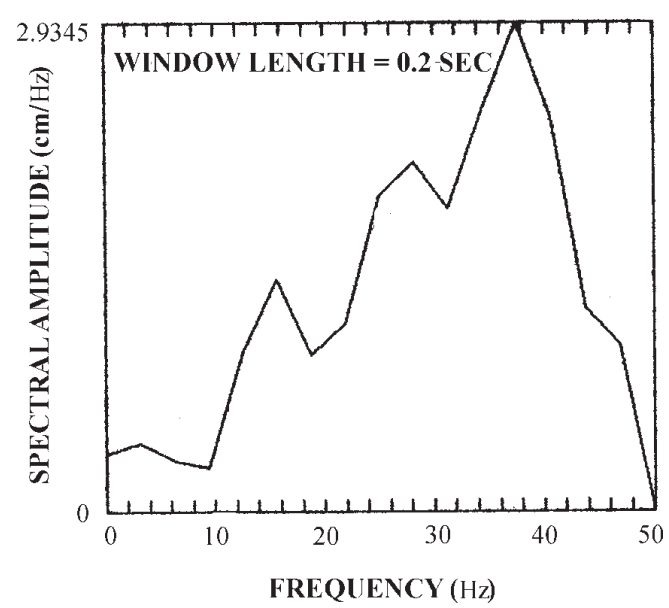

(b)

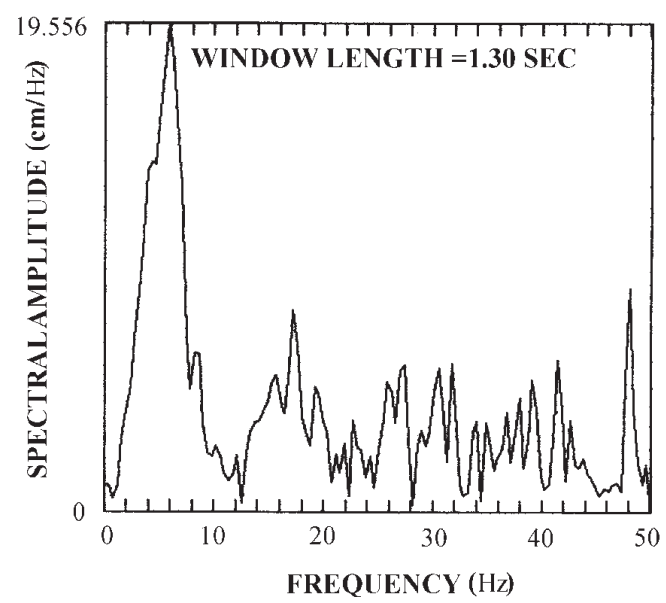

(c)

Figure 7. Waveform at PSJ illustrating the difference in spectra of direct and scattered waves (a). The initial $0.2 \mathrm{~s}$ of the $\mathrm{P}$-wave (the direct wave) exhibits a peak at about $37 \mathrm{~Hz}$ (b). Following the P-direct wave the $1.30 \mathrm{~s}$ duration of the S-wave (direct and scattered waves) spectra exhibits the peak at $5 \mathrm{~Hz}$ (c).

ratio shows stronger dependence on the local site effect than on the directivity of the source.
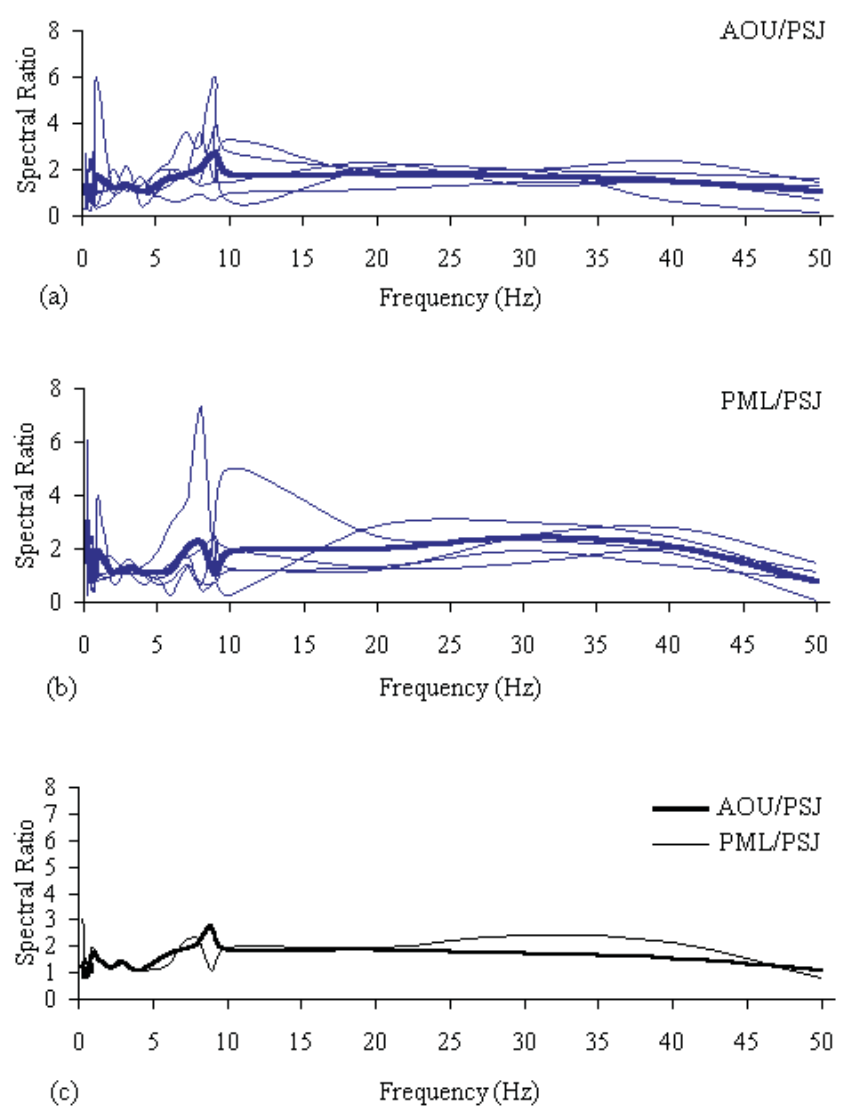

Figure 8. (a) Spectral ratios at AOU/PSJ with spectral ratio for five individual events (event no. 34, 35, 36, 37 and 38 of table 1) (thin lines) and an average spectral ratio, representing all these events (bold line). (b) Similar as in (a) at PML/PSJ. (c) Comparison of average spectral ratios of AOU/PSJ (bold line) and PML/PSJ (thin lines) obtained from (a) and (b).

\section{Discussion}

We analyze the spectra in order to estimate Qp and Qs based on the estimate of amplitude of the spectral content, corner frequency and travel time. Estimations of Qp, Qs, site induced corner frequencies and spectral ratio are made to evaluate the effects of site. The technique adopted in this study is found more suitable than single scattering attenuation model, as the area of study is relatively small. Moreover, the duration of each tremor is so small that the running average with a window of $1.28,2.56$ and $5.12 \mathrm{~s}$ (as used in single scattering model) for these data points after the lapse time of $2 t_{s}$ are not feasible. Qp as estimated for AOU and PSJ are comparatively low while PML execute higher values of $\mathrm{Qp}$ and Qs. While correlating rock type with $\mathrm{Q}$, average $\mathrm{Qp}$ and $\mathrm{Qs}$ value exhibit availability of the hard granitic rock in the region. Average Qs obtained for AOU, PSJ and PML are higher than average Qp with Qs $\sim 1.33 \mathrm{Qp}$. As a matter of fact Qp/Qs provide an 
important constraint for attenuation mechanisms. Rautian et al (1978) reports that Qs is observed to be larger than Qp for paths in the crust near Garm, Tadjikistan so that $\mathrm{t}_{\mathrm{s}} \mathrm{Qs}^{-1} \sim \mathrm{t}_{\mathrm{p}} \mathrm{Qp}^{-1}$. Notably this is reflected in our observation that Qs $\sim 1.33 \mathrm{Qp}$. Possibly this variation is attributable to attenuation mechanism for the associated crustal path. The value of Qs/Qp larger than 1.0 suggests dry crust for most of the Jubilee Hills region. Low Qp and Qs are obtained for $0 \mathrm{~km}$ down to $0.9 \mathrm{~km}$ depth whereas events greater than $0.9 \mathrm{~km}$ depth up to $2.8 \mathrm{~km}$ exhibit higher values of Qp and Qs. Generally $\mathrm{Qp}$ and Qs increase rapidly with depth. In contrast, at shallower depth beneath the Jubilee Hills area, Hyderabad, we obtain high Qp and Qs zone, which correspond to the dense and high velocity rocks of the region. A clear transition zone of varying Qp and Qs connects regions of high and low Qp and Qs. Since all the stations are separated not too far, the maximum distance is 700 meter (radius), the variation of Qp and Qs is obviously caused by the site effect near the station only. In addition, while observing the spectral amplitude ratio of the nearby events, it is different with respect to the travel time. These differences in the travel time ratios when extrapolated to zero reflect response of the receiver site. The magnitudes of the earthquakes used in the study are very low (less than 1.0) and hence, the inferred attenuation characteristics may not exactly be a representative for higher magnitude earthquakes that may occur in near future. The $\mathrm{P}$-wave corner frequencies for the events at these stations vary between 18 and $24 \mathrm{~Hz}$ whereas $\mathrm{S}$-wave corner frequency ranges from 14 to $16 \mathrm{~Hz}$. Thus the non-uniformity of Pwave corner frequencies observed at AOU and PSJ indicates that the corner frequencies of the source spectra of these earthquakes may be covered by the function of the receiving site. The differences in the $\mathrm{P}$-wave spectra are enriched by a higher mode frequency in comparison to S-wave; on the contrary $\mathrm{P}$-wave spectra appear to decrease rapidly at frequencies higher than corner frequencies. In the case of S-wave spectra, the decrease is relatively gradual. These observations generally relate the rupture process only. In the process of determining Qp and Qs values, some nearest events have not been considered. It is observed that (as in figure $5 \mathrm{a}$ and $5 \mathrm{~b}$ ) the spectral ratio points of $\mathrm{S}$-wave varies within 0.2 to $0.3[\log (\mathrm{A} 1 / \mathrm{A} 2)]$ from travel time range of $2.0 \mathrm{~s}$ to a $3.3 \mathrm{~s}$. This variation is not prominent to obtain any gradient value. However travel time greater than $3.3 \mathrm{~s}$ onwards, the spectral ratio data points start decreasing abruptly. The data points above $3.3 \mathrm{~s}$ help to obtain gradiant and intercept through a linear fit required to estimate Qp and Qs values. That is why very near events (maximum six in numbers) are ignored. Since the number of stations used in this study is on the lower side, the attenuation relations estimated may at best be only approximate.

There appears to be a feeble correlation between the spectral ratio at the frequency range of 0.5 to $5.0 \mathrm{~Hz}$ and the near and sub-surface lithology of the area in which the recording stations are located. The correlation can be observed in the range of frequency 5 to $10 \mathrm{~Hz}$ where the northwest part of Jubilee Hills area amplify about twice the impending signal, as compared with the southern part at frequency range from 8 to $10 \mathrm{~Hz}$. In all probability due to the presence of soil, weathered and fractured zone underneath the site of station PML, the seismic signal in a moderately narrow band, is amplified further as compared to the site of station AOU. Thus this is the total effect of soil and fractured zone underneath. Quantification of the above results at several locations with proper litholog information would facilitate a detailed investigation.

\section{Conclusion}

The estimation of Qp and Qs based on the present technique reveals the effect of attenuation and site on microearthquakes originated from the Jubilee Hills region. A displacement spectrum at AOU and PSJ shows that $\mathrm{P}$ waves of these events contain a larger amount of high frequency energy than $\mathrm{S}$ waves. The spectral content has a clear dependence on epicentral distance at lower and higher frequency. Average estimates of Qp and Qs are not equivalent, however higher values of Qs than Qp suggest greater penetration of seismic energy. The study suggests dry crust for most of the Jubilee Hills region as value of Qs/Qp is larger than 1.0. In addition average Qp and Qs values exhibit availability of the hard granitic rock in the region. A low and high Qp and Qs zones are observed at depths. The high Q zone corresponds to the dense and high velocity rocks of the region. Thus a transition zone is demarcated under the Jubilee Hills area which connects regions of high and low Qp and Qs. Hence the variation of Qp and Qs at different stations, for these aftershocks shallower in depth undoubtedly build an estimate of the sitespecific anelastic response of the seismic source and the respective path. Similarly, the varying corner frequencies of the $\mathrm{P}$-wave spectra observed at all the three stations appear to be characteristics of the sites even though the stations are closely spaced. Finally the ratios of station specific spectral content infer that the geological structures of the northwest part of the Jubilee Hills area amplify about twice the impending signal probably due to the presence of soil, weathered 
and fractured zone underneath the site of station PML.

\section{Acknowledgements}

The authors (SB and DH) thank Dr P G Rao, Director, Regional Research Laboratory, Jorhat for giving permission to publish the work and render special thanks to the Department of Science and Technology (DST), Govt. of India, New Delhi. DST provided financial support for this work vide reference no. DST/23(229)/ESS/2000. We are thankful to two anonymous reviewers for their critical comments, which greatly helped to improve the manuscript.

\section{References}

Anderson D L, Ben-Menahem A and Archambeau 1965 Attenuation of seismic energy in the upper mantle; J. Geophys. Res. 70 1441-1448.

Cranswick E 1988 The information content of highfrequency seismograms and the near-surface geologic structure of 'hard rock' recording sites; Pageoph 128 333-363.

Frankel A 1982 The effect of attenuation and site response on the spectra of microearthquakes in the North Eastern Carribbean; Bull. Seismol. Soc. Amer. 72 1379-1402.

Gaur V K and Priestley K F 1997 Shear wave velocity structure beneath the Archean granites around Hyderabad, inferred from receiver function analysis; Proc. Indian Acad. Sci. 106 1-8.
Johnston D H and Toksoz M N 1980 Ultrasonic P- and Swave attenuation in dry and saturated rocks under pressure; J. Geophys. Res. 85 925-936.

Krishnamurthy N S, Kumar D, Rao V A, Jain S C and Ahmed S 2003 Comparision of surface and sub-surface geophysical investigations in delineating fracture zones; Curr. Sci. 84 1242-1246.

Murthy B and Raghavan V 2002 The gravity method in groundwater exploration in crystallite rocks: a study in the peninsular granite region of Hyderabad, India; J. Hydrogeol. 10(2) 307-321.

Rautian T G, Khalturin V I, Martinov V G and Molnar P 1978 Preliminary analysis of the spectral content of $\mathrm{P}$ and $\mathrm{S}$ waves from local earthquakes in the Garm, Tadjikistan region; Bull. Seismol. Soc. Amer. 68 949-972.

Raju P S, Srinivasan A, Raghavan R V and Kousalya M 2000 Microearthquakes activity in Jubilee Hills area of Hyderabad, Andhra Pradesh; J. Geol. Soc. India 55 $443-445$.

Sato H 1977 Energy propogation including scattering effects: single isotropic scattering; J. Phys. Earth 25 $27-41$.

Sato H and Fehler M 1998 Seismic wave propagation and scattering in the Heteorogenous Earth, AIP Press/Spinger Verlag, New York.

Steidl J H, Tumarkin A G and Archuleta R J 1996 What is a reference site?; Bull. Seismol. Soc. Amer. 86 1733-1748.

Singh A P, Vijaya K V and Mishra D C 2004 Subsurface geometery of Hyderabad granite pluton from gravity and magnetic anomalies and its role in the seismicity around Hyderabad, Curr. Sci. 86(4) 580-585.

Vassilou M, Salvado C A and Tittmann B R 1982 Seismic attenuation; In: CRC Handbook of Physical Properties of Rock, III (ed.) R S Carmichael, CRC press, Boca Raton, Florida.

Tsujiura M 1966 Frequency analysis of seismic waves; Bull. Earthquake Res. Inst., Tokyo Univ. 44 873-891. 